European fast reactors

\section{UK committee critical of pact}

DESPITE reservations by a House of Commons Select Committee last month, Britain is to sign a major agreement with five other European nations jointly to develop a commercial fast-breeder nuclear reactor. That is the good news for the UK Atomic Energy Authority (UKAEA). The bad news comes in the government's review of the authority's future, commissioned in 1982 but not published.

The Select Committee on Energy, in its examination of Energy Research, Development and Demonstration in the United Kingdom (HMSO), singled out the fastbreeder programme for particular criticism. It has already cost $£ 2,400$ million and could cost $£ 3,300$ million more before a commercial reactor is in trouble-free operation.

The European collaborative effort entails the construction of three commercial reactors - in Britain, France and West Germany. (The other participants are Italy, the Netherlands and Belgium.) Sir Peter Hirsch, chairman of UKAEA, told the committee that it was necessary to build three reactors in order to satisfy divergent national licensing and operating procedures. The committee says that this seems to preclude common safety and design standards - a prime reason for such a cooperative venture in the first place.

According to the committee, cost savings for Britain would be neligible. Furthermore, it says, there is no evidence that Britain would face insurmountable technical problems if it opted to proceed with the fast-breeder programme alone. In the proposed agreement, Britain's reactor would be the last of the three to be built.

The Select Committee was also critical of the British thermonuclear fusion programme. Although scientific feasibility has always been in question, a major longterm commitment, denied to many less glamorous energy projects, has been made. Sir Hermann Bondi, a former chief scientist at the Department of Energy, is sceptical of the project, claiming that if a commercial fast-breeder reactor were developed, British long-term energy needs would be satiated and the fusion effort would no longer be necessary. On the other hand, if the breeder were to go, then the fusion programme should be scrapped also, as there is no evidence that commercial fusion will pose any less of a waste disposal problem.

These points tend to reinforce the Select Committee's view that nuclear projects are not subject to the stringent reviewing procedures of other energy projects. There is the feeling, fair or not, that, because of the enormous investment made in them, it is impossible to refuse demands for continued funds.

Marcus Chown

Satellite insurance Shuttle to make good failure?

\section{Washington}

THE National Aeronautics and Space Administration (NASA) has formally announced a deal concluded with two insurance syndicates to retrieve and return to Earth the ill-fated Palapa B-2 communications satellite. The satellite belongs to the government of Indonesia and was launched into the wrong orbit last February. Negotiations still in progress could lead to a similar agreement to rescue Western Union Communications' Westar 6 satellite, launched at the same time. If successful, the mission would be a major publicity coup for NASA, which has taken a drubbing over the failure of the shuttle to live up to expectations.

The two satellites, although thought to be undamaged, have been useless since their launch from the shuttle. The failure of the rocket motors on the payload assist modules prevented the satellites from reaching geosynchronous orbit, and both are now in a parking orbit about 560 miles high. The two insurance syndicates involved, International Technology Underwriters of Washington, DC, and Merritt Syndicates Ltd, of London, have agreed to pay NASA $\$ 4.8$ million for the return of Palapa B-2. If (as expected) Westar 6 is eventually included in the package, the bill would be $\$ 5.5$ million surprisingly little compared with the cost of a satellite launch, which can be up to $\$ 70$ million. The advantage to NASA will lie in the public demonstration that the shuttle can be used to return to Earth satellites not designed for retrieval. Hughes Communications will be paid $\$ 2.5$ million for having

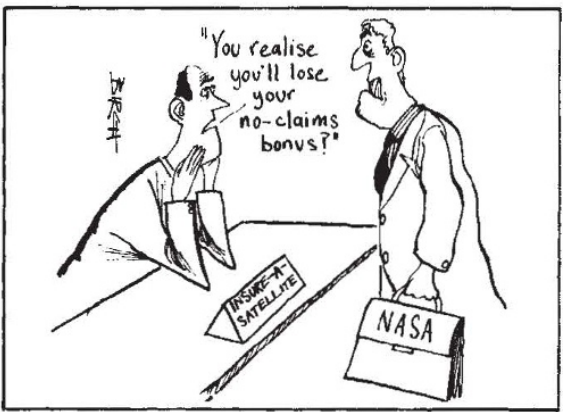

"looked after" Palapa in orbit.

There are still some technical questions to be answered, however. The satellites will first be brought down under their own power to the shuttle's orbit at an altitude of about 200 miles. Both are at present rotating at 55 revolutions per minute and would have to be slowed down enough for an astronaut to approach, while still maintaining gyroscopic stability. The approach by the shuttle orbiter will be carefully contrived so as to avoid its thrusters being fired at the satellites.

If the approach is made successfully, the satellites will be transferred into the payload bay by a complex series of operations involving the shuttle's remote manipulator arm, with the initial contact being made by a free-flying astronaut powered by backpack jets. The loading operation is planned to take about 4 hours per satellite. There could be complications in trying to maintain a suitable temperature, however. The Westar satellite would have to be picked up in an attitude that would allow it to get very cold during loading, and there is concern that this could threaten the operation.

The owners of the two satellites both received substantial insurance payouts when the satellites failed to reach the proper orbit in February. Under the agreement now reached to retrieve Palapa, ownership of the satellite would pass to the insurers before the operation started. The final agreement may include a provision for NASA to recondition the satellite once back on Earth. The price of a new HS 376 communications satellite of the Palapa and Westar 6 type is around $\$ 35$ million. If the rescue is successful, the insurers will thus be the first vendors on the used satellite market. The ownership issue is still not resolved in the case of the Westar satellite, but the deal to retrieve Palapa looks to be settled. The insurers' total loss on the failure in February has been estimated at $\$ 75$ million.

Tim Beardsley

\section{Open University help} for women

AFTER three successful years, a British scheme for providing financial assistance for women taking technical courses at the Open University is to be expanded. The scheme, run by the Manpower Services Commission and previously open only to women with a technical background, will now be extended to include those with no technical experience. Seventy places a year will be provided on the $\mathbf{1 4 2 , 0 0 0}$ a year scheme, compared with the hundred places offered in the past three years.

The technical courses cited for this special treatment, twenty-six in number, include electronics, telecommunications, engineering and computing. Successful applicants for a bursary will be able to embark immediately on one of these courses or, if required, take a first year "technology foundation course". There will be a preliminary "confidence boosting"' weekend at Loughborough University, where students will be helped to identify a direction of study, their own weaknesses and the relevance of any previous job experience. Travel expenses to Loughborough and the annual week-long summer courses will be paid, leaving the bursary holders to contribute just $\mathfrak{£ 4 0}$ towards their yearly fees. Marcus Chown 